\title{
The Biology of Papillomavirus Latency
}

\author{
Gareth Adam Maglennon ${ }^{1}$ and John Doorbar ${ }^{*}, 2$ \\ ${ }^{1}$ Pathology \& Infectious Diseases, The Royal Veterinary College, North Mymms, AL9 7TA, UK \\ ${ }^{2}$ Division of Virology, National Institute for Medical Research, Mill Hill, London, NW7 1AA, UK
}

\begin{abstract}
The presence of viral DNA in the absence of disease has suggested that papillomaviruses, like many other viruses, can exist as latent infections in the skin or other epithelial sites. In animal models, where detailed investigation has been carried out, papillomavirus DNA can be found at sites of previous infection following immune regression, with the site of latent infection being the epithelial basal layer. Such studies suggest that immune surveillance can restrict viral gene expression in the basal and parabasal layers without efficiently suppressing viral genome replication, most probably through the action of memory T-cells in the skin or dermis. Although gradual papillomavirus genome loss appears to occur over time at latent sites, immunosuppression can arrest this, and can lead to an elevation in viral genome copy number in experimental systems. In addition to immune-mediated latency, it appears that a similar situation can be achieved following infection at low virus titres and/or infection at epithelial sites where the virus life cycle is not properly supported. Such silent of asymptomatic infections do not necessarily involve the host immune system and may be controlled by different mechanisms. It appears that virus reactivation can be triggered by mechanical irritation, wounding or by UV irradiation which changes the local environment. Although the duration of papillomavirus latency in humans is not yet known, it is likely that some of the basic principles will resemble those elucidated in these model systems, and that persistence in the absence of disease may be the default outcome for at least some period of time following regression.
\end{abstract}

Keywords: Papillomavirus, HPV, latency, basal cell, stem cell, immune regression, immunosuppression.

\section{INTRODUCTION}

Infection of a host with a virus can have several outcomes. An acute infection may develop that is followed by recovery from the virus (or in some cases, death) and complete elimination of the virus from the host. Alternatively, a chronic or persistent infection may result, with long-term carriage of the virus with or without further bouts of acute disease. Instead of viral clearance following infection, a state of viral latency may develop, during which no clinical signs of disease are apparent and new virus particles are not produced and released. It is possible that such a latent infection may undergo subsequent reactivation leading to new virion synthesis, with or without the reemergence of clinical disease. Many viruses have a latent stage to their life cycle, and it has long been considered that papillomaviruses are no different. The classic model of viral latency is perhaps the alphaherpesvirus, Herpes Simplex Virus-1 (HSV-1), the cause of labial cold sores and with which at least $90 \%$ of the general population are infected [1]. Following an acute and productive infection of epithelial cells usually early in life, HSV-1 migrates by retrograde axonal transport along sensory neurones and enters a latent phase in nuclei in the sensory ganglia [2]. This serves as a reservoir of infection from which anterograde transport can lead to recurrent disease later in life, often in response to factors such as immune suppression [3]. HSV-1 latency is

*Address correspondence to this author at the Division of Virology, National Institute for Medical Research, Mill Hill, London, NW7 1AA, UK; Tel +44 208816 2623; Fax +44 208906 4477;

E-mail: jdoorba@nimr.mrc.ac.uk very well characterized, but for papillomaviruses, this level of detail does not yet exist. Much of the evidence for latent papillomavirus infections in humans is based on clinical observations and is often anecdotal because of ethical concerns associated with the collection of biopsy samples from humans that may have latent virus, but no signs of clinical disease. Such clinical observations include the higher incidence of cervical papillomavirus infection in human immunodeficiency virus (HIV) seropositive versus seronegative patients, which may result from the reactivation of latent papillomavirus infection following immunosuppression [4-6]. Similarly, organ transplant recipients undergoing iatrogenic immunosuppression have a higher incidence of high-risk papillomavirus type infections that are associated with cervical neoplasia [7-9] and it has been considered that in many of these cases, reactivation of a dormant or latent infection may be important $[10,11]$. Genital infections with low-risk HPVs such as HPV-6 and HPV-11 are also considered to cause latent infections [12], which may account for the high recurrence rates of genital papillomas following treatment $[12,13]$. Similarly, latent HPV-6 and HPV-11 infection of the mucosal lining of the upper airways of individuals with recurrent respiratory papillomatosis (RRP) may be one of the factors responsible for the frequent and multiple recurrences of papillomas [14-18]. These observations and the limitations of studying latency in humans, has driven investigators to make extensive use of animal models of infection. In most cases, a better understanding of HPV latency has been the primary objective, although it appears that some economically important animal diseases may also be associated with latent 
infection. These include BPV4-associated urinary bladder cancers in cattle [19-22], and equine sarcoids in horses, which are associated with BPV1 and BPV2 [23-27]) and which constitute the most common equine skin tumour [23, 24]. BPV 1 and BPV 2 DNA can be detected in the normal skin of horses affected by equine sarcoids, and the occurrence of sarcoids at sites of skin wounding and/or following physical trauma suggests a possible reactivation from latency [25-27]. Similarly, the frequent detection of BPV-4 DNA in normal bovine bladder mucosa has suggested its presence as a latent infection that can undergo reactivation when cattle graze on pastures rich in bracken fern [21]. BPV4 is thus considered as a model of the synergistic actions of a chemical and a biological agent in carcincogenesis as well as a model of papillomavirus latency.

\section{ANIMAL MODELS FOR THE STUDY OF PAPILLO- MAVIRUS INFECTION AND LATENCY}

Understanding the natural history of papillomavirus infection and latency, has until recently been hampered by the lack of convenient laboratory animal models. Papillomaviruses have been isolated from a diverse range of domestic and wild species, but for laboratory studies, rats and mice are generally preferred because of their small size and because of the availability of validated biological reagents and transgenic mutant mouse strains. Papillomaviruses have been found to cause cutaneous papillomas and sebaceous carcinomas in the European Harvest Mouse (MmPV which infects micromys minutus) [28], as well as the oral cavity of hamsters (mesocricetus auratus) [29], but transmission to naïve animals and/or laboratory species has not been reported. More recently, papillomaviruses have been detected in clinically normal oral tissues in wild rats (Rattus norvegicus) [30], and perhaps more importantly, in papillomas from immunocompromised laboratory mice (Mus musculus) [31]. These rodent papillomaviruses are contained within the Pi Genus [32], and are related (albeit distantly) to the Gamma and Beta types that cause asymptomatic infection in humans. While musPV is not a perfect model of infection and disease caused by the high-risk Alpha types, it will allow us to elucidate the basic mechanisms of PV latency and the role of the immune system in the years to come, and it is likely that much of this work will be relevant to human disease. Other small animal models used to study papillomavirus latency include the African natal multimammate rat (Mastomys natalensis), which is associated with both inapparent disease and cancers in its natural host [33-35]. The multimammate rat is an unconventional laboratory animal however, and as a result of this, its widespread use has been restricted.

The limited availability of well-characterized rodent models, (as described above), has meant that most previous work on papillomavirus latency has focused on larger domesticated animals, and in particular on rabbits, dogs and cattle. Canine oral papillomavirus (COPV) is a naturally occurring mucosal papillomavirus that does not usually cause problematic clinical disease, except in rare instances where the virus can cause severe non-regressing papillomatosis [36]. Experimental infection of the oral mucosa leads to the formation of large papillomas within four to eight weeks, followed by spontaneous immune- mediated regression [37]. As a mucosal virus, COPV has been proposed as an animal model of HPV 6 and 11associated RRP in humans [38], and has also been used in vaccine development [39-42], and to investigate the immune response to infection $[37,43]$. Despite the apparent similarities in tissue tropism, COPV and HPVs have a number of organizational differences, which emphasize the general need for caution when using animal models. COPV contains a $1.5 \mathrm{kbp}$ regulatory region between $\mathrm{E} 2$ and $\mathrm{L} 2$ that is not present in HPVs [44], and in the lesions that COPV causes, viral genome amplification begins in a subset of infected basal cells rather than being restricted to only the suprabasal cell layers [45, 46]. Rabbit oral papillomavirus (ROPV) has a similar tropism to COPV, and induces spontaneously regressing and benign papillomas in domestic rabbits [28, 47]. Experimental infection gives rise to papillomas that form over a period of four weeks or so, followed by immune-mediated regression [48, 49]. On the basis of life-cycle organization and genome similarities, ROPV appears to more closely mimic the low-risk mucosal HPV types such as HPV-6 and HPV-11 [46], and infects genital tissue in both male and female rabbits [48]. Domestic rabbit (Oryctolagus cuniculus) can also be infected with an entirely different papillomavirus, the Cottontail Rabbit Papillomavirus (CRPV), whose natural host is the cottontail rabbit (Sylvilagus floridanus) native to the Americas. While ROPV has a tropism for oral epithelium, CRPV has a tropism for cutaneous epithelium, with papillomas appearing around four weeks after experimental infection of domestic rabbits [50]. Approximately $10 \%$ of papillomas undergo spontaneous regression in domestic rabbits, with $60-75 \%$ being persistent and progressing to squamous cell carcinoma $[51,52]$, and because of this, CRPV has been used as a model of high-risk HPV disease. In addition to the papillomaviruses found in rabbits and dogs, more than 10 different bovine papillomaviruses (BPV) have so far been described. The size of the bovine host, and the expense and difficulties surrounding animal management has limited the use of cattle as an in vivo model system. Finally, a model system of cervical papillomavirus infection does exists in the rhesus macaque, with this model being used to advance our understanding of the biology of HPV cervical infection [53], although as yet, not our understanding of latent infections.

\section{EVIDENCE FOR THE PERSISTENCE OF PAPILLO- MAVIRUSES AS LATENT INFECTIONS}

The persistence of papillomaviruses in a latent state necessitates the maintenance of the viral genome in the infected cell, either as an episome or integrated into the host cell DNA. Persistence in the absence of clinical disease does not necessarily exclude viral activities required for genomemaintenance, such as low-level viral genome replication and production of viral transcripts and proteins (described in more detail below). CRPV was one of the first papillomaviruses used to investigate papillomavirus latency, and in this system, the inoculation of rabbit skin with high concentrations of virus rapidly leads to the formation of large papillomas. By contrast, inoculation with low concentrations of virus does not lead to papilloma formation, although viral DNA can be detected at the site of inoculation for as long as 18 weeks after infection [54] (Fig. 1). Such 'asymptomatic' or 'silent' infections were accompanied by 
low-level expression of CRPV E1 transcripts, suggesting a possible requirement of the viral E1 helicase [55]. While these studies support the general concept of persistence in the absence of overt disease, they have not established whether persistence can also occur following immunemediated disease-regression (Fig. 1). This has however been examined in separate studies using CRPV and COPV, and more recently, and in more detail, using ROPV [49]. In none of these systems could the site of latent infection be established using DNA in situ hybridization methods, suggesting that the genome copy number per infected cell is very low $[45,49,56]$. Such approaches have only limited sensitivity however, and do not generally detect papillomavirus genomes even in the basal layer of productive papillomas. Using more sensitive PCR approaches, low levels of papillomavirus DNA could clearly be detected at sites of previous infection in all three systems, with persistence for at least a year post-infection in the absence of clinical signs of disease $[45,49,56]$. Although the heterogeneous nature of papillomas complicates copynumber estimation in the basal and suprabasal cell layers, the papillomavirus burden was reported to drop from around 7.5 genome copies per cell in warts, to as little as one genome copy per 40-1000 cells following lesion clearance [56]. Our more detailed studies of ROPV-infected rabbits suggest a similar scenario. Following immune-regression, ROPV genomic DNA was present at levels that were up to $6 \operatorname{logs}$ lower than in mature papillomas. Such results are consistent with the presence of genomes in only a small fraction of cells, and with a lack of significant genome amplification in the upper layers of the epithelium [49]. It appears that following experimental infection at least, viral latency is a common sequela to papilloma regression, with latent genomes being detected in the majority of tissue samples obtained from the majority of rabbits $[49,56]$. For these papillomavirus types, and we suspect for other types too, viral latency may be a typical outcome of disease resolution by the immune system, as happens for example with HSV-1.

For low-risk papillomavirus types such as ROPV or HPV11, it has been suggested that papilloma formation requires virus entry and genome maintenance in an epithelial stem cell [57]. Lesion-persistence may depend on the longevity of this cell, with viral genome-containing daughter cells (i.e. the infected transiently amplifying cells) populating the epithelial basal layer around the infected stem cell as it undergoes normal cell-division. Following immuneregression, it is thought that such infected stem-cells may harbour latent papillomavirus genomes, with reactivation occurring following changes in host immune-status, or following changes in the level of hormones, cytokines and/or growth factors $[45,55]$. In our ROPV study, we were able to specifically localize latent viral genomes using laser capture microscopy to the basal cells of the epithelium [49]. In the population of basal cells examined using this approach, viral genomes were often detected at less than one copy per cell, suggesting that only a subset of basal cells, and possibly the basal stem cells were infected $[58,59]$. Despite observing viral DNA in the basal layer, we only rarely found evidence of viral genome amplification in the cell layers above, suggesting that the virus may be maintained in a quiescent or inactive state in cells with a capacity for self-renewal. As seen in asymptomatic CRPV infections [55], viral transcripts were reproducibly present in latently infected ROPV tissues [49], and in addition to E1 transcripts, other early mRNA species (E2, E6), including spliced forms, were detected. It is possible that the control of viral gene expression following immune regression may be different from that seen following low-titre infection where the low-level expression of E1 mRNAs were observed. Despite extensive analysis of tissue sections, we have not yet been able to detect late viral proteins at sites of previous infection $\left(\mathrm{E} 1^{\wedge} \mathrm{E} 4\right.$ and $\left.\mathrm{L} 1\right)$, supporting the idea that genome amplification and virus synthesis does not occur or is rare. Thus, for ROPV infection at least, the post-regression genomes appear truly latent.

\section{ACTIVATION AND REACTIVATION OF LATENT PAPILLOMAVIRUS}

From the work described thus far in animal models, it has been shown that papillomavirus genomes can persist in the absence of clinical or microscopic signs of disease. However, of greater importance is to attribute some significance to this and to define the importance and potential consequences of such persistence. Anecdotal tales suggest that latent human papillomavirus infections can sometimes undergo reactivation leading to disease recrudescence. The high recurrence rate of low-risk genital HPV-6 and 11 infections following treatment is often attributed to the reactivation of latent papillomavirus infections [12]. Immune suppression, either iatrogenic and drug-induced following organ transplantation, or secondary to HIV infection, appears to facilitate papillomavirus reactivation, and has been well documented in the case of Beta HPV disease [10, 11, 60-63]. Finally, in individuals suffering from recurrent respiratory papillomatosis (RRP), the high recurrence rates at sites of previous infection, and the demonstration of viral DNA and RNA transcripts in the absence of clinical lesions has led to the suggestion that latency may underlie recurrence in susceptible patients [15$18,64,65]$. The study of animal models has provided an opportunity to define the factors involved in reactivation more precisely. Mastomys Natalensis Papillomavirus (MnPV) infection of the multimammate rat appears to represent an 'endogenous infection', with extrachromosomal viral genomes being present in a variety of organs in laboratory colonies [35]. Although an unusual model system, $\mathrm{MnPV}$ has given us some intriguing insights into viral latency. Typically in the young animal, MnPV DNA is present at low copy number in the skin in the absence of clinical signs of disease. Following repeated chronic mechanical irritation of the skin with fine glasspaper over a period of eight weeks, a 58 -fold increase in viral DNA copy number was detected compared to non-irritated skin [34]. With the same treatment regime applied over a period of 67 weeks, there was a significant increase in the formation of cutaneous tumours when compared to the skin of nonirritated mice. A similar effect was described when a tumour promoter, tetradecanoyl-phorbol-13-acetate (TPA) was applied to the skin [35]. These findings would suggest that stimulation of cellular proliferation and induction of epithelial hyperplasia, either by chronic mechanical irritation or by application of compounds, is sufficient to promote the activation of apparently latent papillomavirus genomes. The 


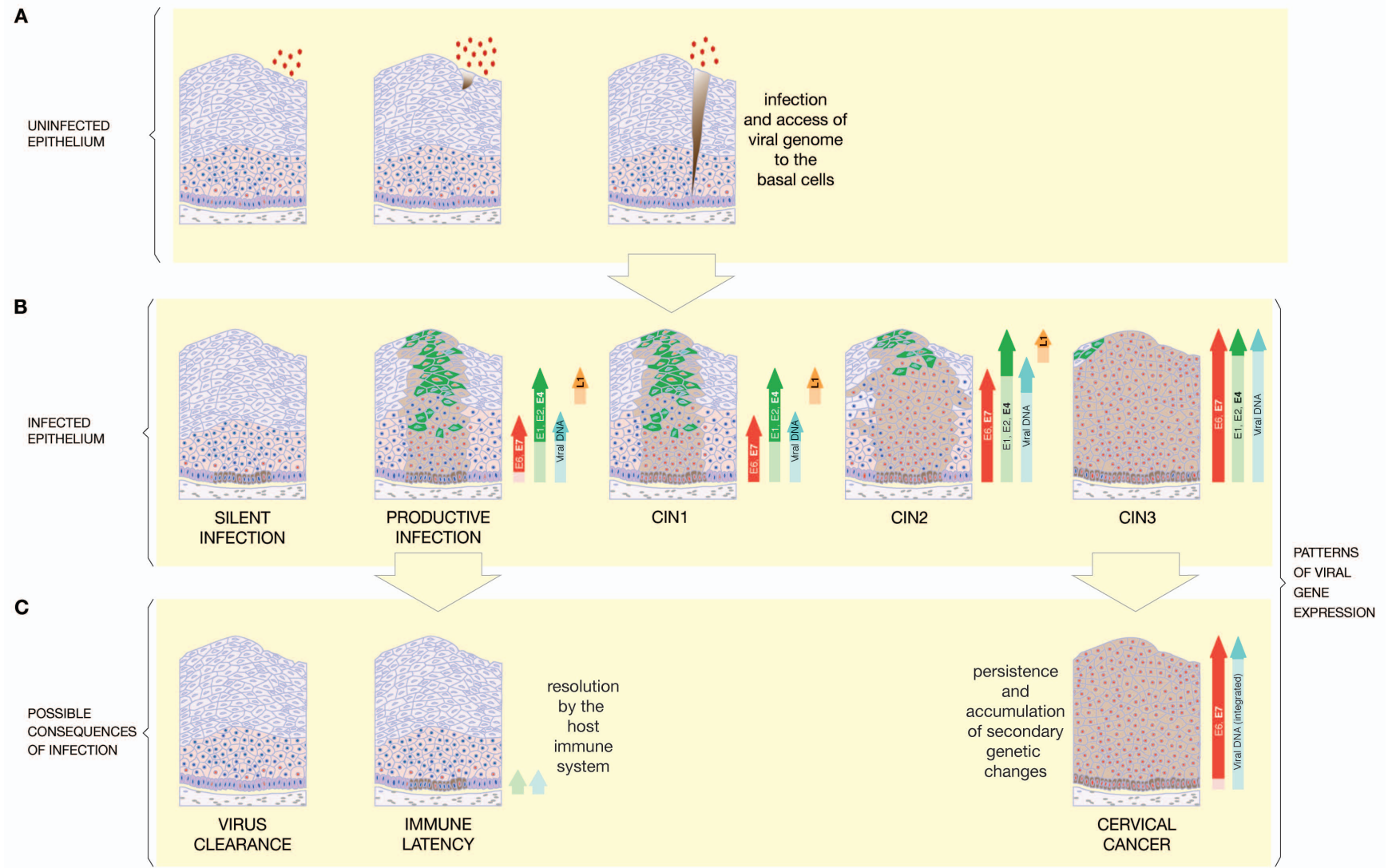

Fig. (1). Different Outcomes of Papillomavirus Infection. (A) Papillomavirus DNA can be detected in epithelial tissues because of its presence as virus particles on the epithelial surface. The detection of papillomavirus DNA in such situations can be misinterpreted as papillomavirus latency. To cause a lesion and/or to initiate a latent infection, the virus particles have to gain access to the epithelial basal cells at sufficiently high levels. Each papillomavirus type has specific epithelial sites where it can initiate a productive life cycle, as well as sites where virus entry occurs in the absence of lesion formation. Such epithelial tropisms are not yet understood at the molecular level. (B) Depending on the epithelial site, the virus titre, and the tropism of the particular papillomavirus, it appears that several outcomes can result. At low titres and/or at non-permissive epithelial sites, an asymptomatic or silent infection may ensue, in which viral genomes may persist in the basal layer without appropriate gene expression or lesion formation. While this is a form of latency, such silent infections do not necessarily involve the immune system, and are distinguished here from latency mediated by the immune-system Alternatively a productive infection may develop, in which viral gene expression is properly regulated as the infected cell migrates through the epithelium. With some HPV types (e.g. high-risk types) and at particular epithelial sites, deregulated viral gene expression can lead to neoplasia. Cervical Intraepithelial Neoplasia (CIN) of different grades can occur following high-risk HPV infection of the cervix. (C) Persistent high-risk HPV infection can predispose to the accumulation of genetic errors and the progression to cancer at certain epithelial sites (e.g. the cervical transformation zone). Most infections are transient however and are resolved by the host immune system. Although immune surveillance may suppress viral gene expression in the epithelium, failure of the immune system to clear viral genomes from the epithelial basal layer would explain papillomavirus latency.

importance of mechanical irritation has also been demonstrated in the establishment of CRPV papillomas. Mechanical irritation of rabbit skin prior to infection with CRPV virions or genomes enhanced infectivity, but it is not clear whether or not such treatment has an effect on latent CRPV infection [66]. In our own studies on rabbits infected with ROPV, we were not able to reactivate latent infection by mechanically wounding previously-infected tongue tissue, although this may be largely due to accessibility difficulties and the sensitive nature of the tissue which precluded multiple treatments being applied over time. It would appear from the MnPV model that chronic mechanical irritation is necessary. The CRPV model has however provided additional useful insights. After inoculation of Cottontail Rabbits with a low dose of virus, Zhang et al. investigated the response of latent viral genomes to exposure to ultraviolet light [55]. During the asymptomatic phase of infection, when viral genomes were present in the absence of lesions, analysis of tissue biopsies by reverse-transcription PCR and Southern blotting revealed the presence of E1 transcripts which may be necessary for the maintenance of the viral genomes in infected cells [67], but not E6 and E7 transcripts associated with stimulation of cellular proliferation. As little as one week after irradiation with ultraviolet light, the authors were able to detect E6 and E7 mRNA at the sites of infection, with papillomas developing subsequently at some locations. It appears in this system, that expression of E1 may play a role in maintenance of the virus as a latent infection, but that E6 and E7 expression were needed for activation to form clinical lesions. The 
universal requirement for $\mathrm{E} 1$ has recently been questioned however, and it has been speculated that some PV types may be able to persist in the basal layer in the absence of this PVspecific replication protein [68]. In our work on rabbits infected with ROPV, we detected E6 and E7 transcripts as well as E1 and E2 transcripts at low levels during latency, but at vastly reduced copy number compared to productive infection [49]. The detection of transcripts cannot be equated to expression of protein, but it seems possible that low levels of early viral proteins may be necessary during papillomavirus latency, but that the precise requirements may differ depending on papillomavirus type and possibly also on whether latency is controlled by the immune system or has resulted from low titre infection. In both situations however, the expression of viral proteins is likely to be low in order to avoid immune stimulation.

Whether or not viral proteins are produced during latency, the host immune system is likely to be central to the regulation of the latent state. Studies of experimental animal infections have been valuable in determining the sequence of events that lead to the spontaneous regression of papillomas and in defining the nature of the host immune response to papillomavirus infection. Regression of papillomas is typically associated with a heavy infiltrate of T-cells and macrophages into the epithelium and underlying stromal tissue leading to rapid lesion clearance $[37,56,69]$. In these systems, the cell-mediated immune response would appear to be directed particularly against the early proteins E6 and E2 and is maximal just prior to regression $[43,70]$. Following regression, antibodies directed against the $\mathrm{L} 1$ capsid protein can be detected and may protect against subsequent challenge [36]. We believe that continual immune surveillance is key in maintaining papillomaviruses in a latent state as is the case with other DNA viruses that enter latency, such as HSV-1 [3, 71], and the presence of memory T-cells in the epithelium provides us with a mechanism by which this may be achieved [72] (Fig. 2). Interestingly, recent studies in humans have suggested that latent HPV infections may be associated with particular methylation patterns on the viral episome and presumably also with limited gene expression [73]. If our hypothesis that recurrence in HIV-infected individuals and renal transplant recipients is due to the reactivation of latent infections, then a waning immune response would appear to be necessary to facilitate recurrence. In the CRPV model of asymptomatic infection described earlier, a low level virus inoculation was found to be insufficient to allow papilloma formation, and probably also insufficient to stimulate a strong cell-mediated immune response against viral antigens $[54,55]$. Therefore, subsequent exposure to ultraviolet light and induction of a DNA damage response would be sufficient to allow activation of the virus in the absence of a robust immune response. According to this model, we have examined whether latent ROPV can be reactivated by drug-induced suppression of the host immune system. Our unpublished data suggest that a prolonged period of immune suppression does stimulate early events during reactivation, with evidence of an elevation in viral genome copy number at sites of latent infection. These experiments have however been challenging because of the difficulty of inducing a chronic state of immune suppression in rabbits. Recently, a novel papillomavirus (MusPV) has been isolated from a laboratory mouse [31]. MusPV has a tropism for cutaneous epithelium, and crude virus preparations and DNA have been successfully used to induce the appearance of discrete benign papillomas in immunocompromised mice. The genome of MusPV has been fully sequenced and has been classified as a member of the Pi genus, with it's closest relatives being other rodent papillomaviruses [74]. Such a mouse model has obvious value for the study of papillomavirus latency, given the availability of immunodeficient strains of Mus musculus and the ability to suppress and deplete components of the host immune system and it is hoped that the MusPV genome will soon become available to the papillomavirus research community. Furthermore, by causing cutaneous disease on readily accessible areas of the body, opportunities may be afforded to investigate other factors that are important in reactivation, such as chronic wounding and application of substances.

\section{A PROPOSED MODEL OF PAPILLOMAVIRUS LATENCY}

Primarily through studies of experimental animal infections, we are beginning to define and understand papillomavirus latency. Drawing together results of experiments performed in animals, supported by clinical observations in humans, we can build a proposed model of how a latent stage of the papillomavirus life cycle may occur. Although some papillomaviruses may have specific ways to access the epithelial basal cell layer (e.g. via the squamo-columnar junction or via hair follicles), in many cases it is thought that papillomaviruses gain access to basal cells of the epithelium via cuts or abrasions, and that the establishment and maintenance of infection requires entry into a long-lived cell such as the epithelial stem cell [57]. Following infection, there are two potential outcomes. A clinically apparent lesion may form as is seen for example with ROPV infection of the rabbit tongue with virions. In other cases, a clinically silent infection may develop, that may or may not involve the completion of the full productive virus life cycle (Fig. 1). Such an infection has been observed in rabbits infected with a low dose of CRPV [54, 55]. Where new virions are not formed, this may represent a form of viral latency, but in this situation, there is unlikely to be immune cell involvement. Following the 'apparent' clearance of an acute productive infection, viral latency may also ensue, in which a fraction of basal epithelial cells (possibly the epithelial stem cells or stem-like cells) retain viral genomes, most probably in the form of episomal DNA (Fig. 2). In the absence of a strong immune response, factors such as a DNA damage response, or the stimulation of cellular proliferation by wounding will stimulate proliferation of cells harbouring viral DNA. In turn, lesions may form, as appears to occur in latent CRPV infection, following exposure to UV light [55]. Alternatively, where latency has developed following lesion regression driven by a strong cell-mediated immune response, we believe that subsequent virus reactivation may occur upon suppression of the immune system. A weakened immune system is likely to allow virus-infected cells to undergo proliferation with completion of the productive virus life cycle, with or without the re-emergence of lesions (Fig. 2). For studies of virus reactivation in particular, we expect that animal models will play a key role in the further development of these models. 

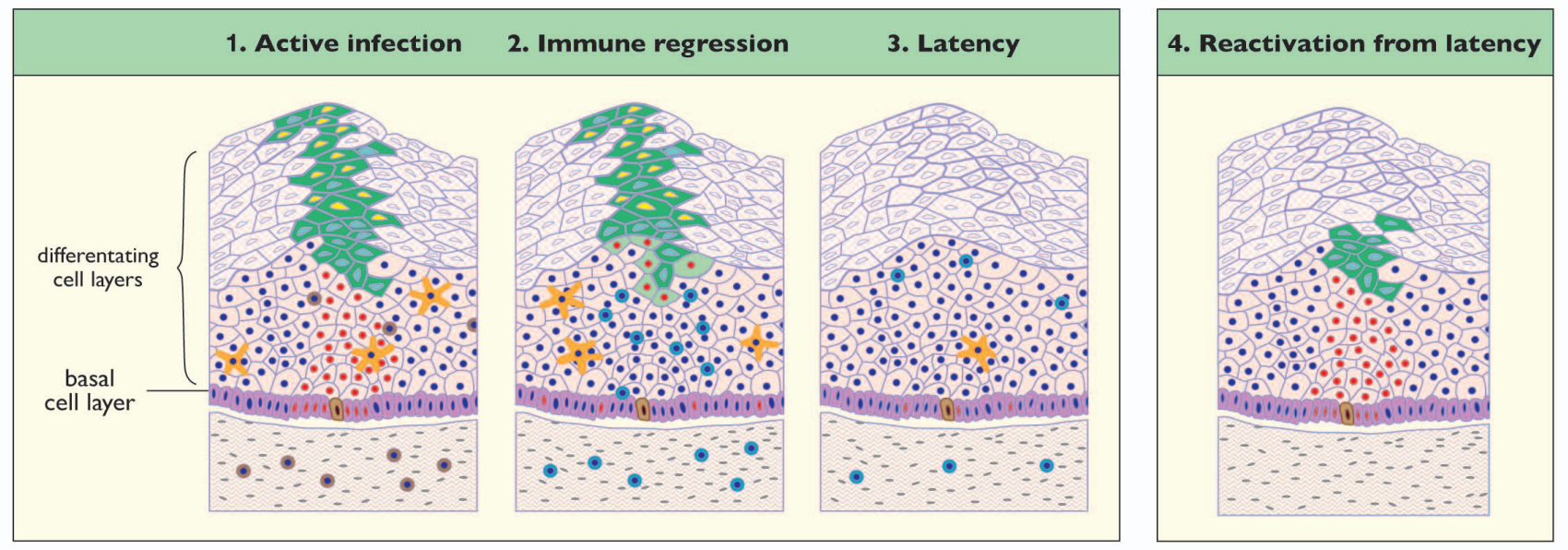

Fig. (2). Model of Papillomavirus Latency based on Animal Studies. (1) Active Infection. Active papillomavirus infection involves the regulated expression of viral proteins as cells containing viral genomes migrate towards the epithelial surface. The onset of viral genome amplification (light blue) and L1 expression (yellow) facilitates the assembly and eventual release of virions from the epithelial surface. Cells that are 'in the cell cycle' and which may proceed through cell division are marked with red nuclei. In the upper epithelial layers, cell cycle entry is driven by the viral E6 and E7 proteins. The virus-infected cells of the epithelial basal layer maintain the viral genome as a low copynumber episome with only low-levels of viral gene expression. Long-term persistence may require the maintenance of the viral genome in an epithelial 'stem cell' (highlighted in the basal layer). Resting T-cells (brown) and Langerhans cells (orange) can be found in the lower layers of the epithelium and in the dermis. The positions of these resting T-cells (brown circular cells) are indicated in the diagram. (2) Immune Regression. Immune regression involves the presentation of viral antigens to the immune system, (probably via the Langerhans cells) and the subsequent accumulation of activated CD4+ and CD8+ T-cells (light blue circular cells) in and around the lesion. During regression, activated T-cells accumulate within and beneath the lesion. (3) Latency. Lesion clearance involves the suppression of viral gene expression as lymphocytes infiltrate, and may involve changes in cytokine activity and cytokine signaling at the site of regression. The ongoing proliferation of virus-containing basal cells in the absence of normal viral gene expression appears to underlie lesion clearance. Changes in viral gene expression in the replicating basal cells may explain the slow decline in viral genome copy number over time at the site of previous infection. Current thinking suggests that the papillomavirus genome may persist long-term in the slow-cycling stem cells or stemlike cells. (4) Reactivation from Latency. This model may explain the changes in viral copy number that are thought to accompany immunosuppression. The presence of memory T-cells circulating in the epithelium prevent extensive viral gene expression and keep the viral genomes in the basal layer in a latent state. Changes in immune status would allow local rises in viral copy-number, and the possible reappearance of visible papillomas.

\section{CONCLUDING REMARKS}

Clinical observations of humans and animals infected with papillomaviruses have for a long time led to the assumption that papillomaviruses can form latent infections. Our understanding of papillomavirus latency has been substantiated by a limited number of studies using experimental animal models of infection carried out in relatively few labs. However, despite the important advances that have been made, our overall understanding of papillomavirus latency is still very much in it's infancy, particularly when compared to the vast wealth of knowledge pertaining to other viral infections. The ubiquity of HPVs and their mounting association with a growing range of diseases (including severe papillomatosis and diverse cancers), is directing more interest towards the understanding of papillomavirus latency. The recent discovery of a laboratory mouse papillomavirus is a significant and long-awaited advancement in the field, and one that will hopefully allow us to address the many unanswered questions that remain.

\section{CONFLICT OF INTEREST}

The authors confirm that this article content has no conflict of interest.

\section{ACKNOWLEDGEMENTS}

The authors were funded by a program grant from the United Kingdom Medical Research Council (U117584278). Gareth Maglennon received funding from Sanofi Pasteur MSD (Lyon, France) and from the Wellcome Trust in the form of a Research Training Fellowship (082155/Z/07/Z).

\section{REFERENCES}

[1] Perng GC, Jones C. Towards an understanding of the herpes simplex virus type 1 latency-reactivation cycle. Interdiscip Perspect Infect Dis 2010; 2010: 1-18.

[2] Efstathiou S, Preston CM. Towards an understanding of the molecular basis of herpes simplex virus latency. Virus Res 2005; 111(2): 108-19.

[3] Decman V, Freeman ML, Kinchington PR, Hendricks RL. Immune control of HSV-1 latency. Viral Immunol 2005; 18(3): 466-73.

[4] Jamieson DJ, Duerr A, Burk R, et al. Characterization of genital human papillomavirus infection in women who have or who are at risk of having HIV infection. Am J Obstet Gynecol 2002; 186(1): $21-7$

[5] Moscicki AB, Ellenberg JH, Vermund SH, et al. Prevalence of and risks for cervical human papillomavirus infection and squamous intraepithelial lesions in adolescent girls: impact of infection with human immunodeficiency virus. Arch Pediatr Adolesc Med 2000; 154(2): 127-34.

[6] Palefsky JM, Minkoff H, Kalish LA, et al. Cervicovaginal human papillomavirus infection in human immunodeficiency virus-1 
(HIV)-positive and high-risk HIV-negative women. J Natl Cancer Inst 1999; 91(3): 226-36.

[7] Ozsaran AA, Ates T, Dikmen Y, et al. Evaluation of the risk of cervical intraepithelial neoplasia and human papilloma virus infection in renal transplant patients receiving immunosuppressive therapy. Eur J Gynaecol Oncol 1999; 20(2): 127-30.

[8] Paternoster DM, Cester M, Resente C, et al. Human papilloma virus infection and cervical intraepithelial neoplasia in transplanted patients. Transplant Proc 2008; 40(6): 1877-80.

[9] Veroux M, Corona D, Scalia G, et al. Surveillance of human papilloma virus infection and cervical cancer in kidney transplant recipients: preliminary data. Transplant Proc 2009; 41(4): 1191-4.

[10] Savani BN, Stratton P, Shenoy A, Kozanas E, Goodman S, Barrett AJ. Increased risk of cervical dysplasia in long-term survivors of allogeneic stem cell transplantation--implications for screening and HPV vaccination. Biol Blood Marrow Transplant 2008; 14(9): 1072-5.

[11] Savani BN, Goodman S, Barrett AJ. Can routine posttransplant HPV vaccination prevent commonly occurring epithelial cancers after allogeneic stem cell transplantation? Clin Cancer Res 2009; 15(7): 2219-21.

[12] Lacey CJ. Therapy for genital human papillomavirus-related disease. J Clin Virol 2005; 32 (Suppl 1): S82-90.

[13] von Krogh G, Lacey CJ, Gross G, Barrasso R, Schneider A. European course on HPV associated pathology: guidelines for primary care physicians for the diagnosis and management of anogenital warts. Sex Transm Infect 2000; 76(3): 162-8.

[14] Steinberg BM, Topp WC, Schneider PS, Abramson AL. Laryngeal papillomavirus infection during clinical remission. N Engl J Med 1983; 308(21): 1261-4.

[15] Abramson AL, Nouri M, Mullooly V, Fisch G, Steinberg BM. Latent Human Papillomavirus infection is comparable in the larynx and trachea. J Med Virol 2004; 72(3): 473-7.

[16] Pignatari S, Smith EM, Gray SD, Shive C, Turek LP. Detection of human papillomavirus infection in diseased and nondiseased sites of the respiratory tract in recurrent respiratory papillomatosis patients by DNA hybridization. Ann Otol Rhinol Laryngol 1992; 101(5): 408-12.

[17] Smith EM, Pignatari SS, Gray SD, Haugen TH, Turek LP. Human papillomavirus infection in papillomas and nondiseased respiratory sites of patients with recurrent respiratory papillomatosis using the polymerase chain reaction. Arch Otolaryngol Head Neck Surg 1993; 119(5): 554-7.

[18] Maran A, Amella CA, Di Lorenzo TP, Auborn KJ, Taichman LB, Steinberg BM. Human papillomavirus type 11 transcripts are present at low abundance in latently infected respiratory tissues. Virology 1995; 212(2): 285-94.

[19] Campo MS. Bovine papillomavirus and cancer. Vet J 1997; 154(3): 175-88.

[20] Campo MS, Jarrett WF, Barron R, O'Neil BW, Smith KT. Association of bovine papillomavirus type 2 and bracken fern with bladder cancer in cattle. Cancer Res 1992; 52(24): 6898-904.

[21] Borzacchiello G, Iovane G, Marcante ML, et al. Presence of bovine papillomavirus type 2 DNA and expression of the viral oncoprotein E5 in naturally occurring urinary bladder tumours in cows. J Gen Virol 2003; 84(Pt 11): 2921-6.

[22] Campo MS, Jarrett WF, O'Neil W, Barron RJ. Latent papillomavirus infection in cattle. Res Vet Sci 1994; 56(2): 151-7.

[23] Valentine BA. Survey of equine cutaneous neoplasia in the Pacific Northwest. J Vet Diagn Invest 2006; 18(1): 123-6.

[24] Chambers G, Ellsmore VA, O'Brien PM, et al. Association of bovine papillomavirus with the equine sarcoid. J Gen Virol 2003; 84(Pt 5): 1055-62.

[25] Carr EA, Theon AP, Madewell BR, Griffey SM, Hitchcock ME. Bovine papillomavirus DNA in neoplastic and nonneoplastic tissues obtained from horses with and without sarcoids in the western United States. Am J Vet Res 2001; 62(5): 741-4.

[26] Bogaert L, Martens A, Kast WM, Van Marck E, De Cock H. Bovine papillomavirus DNA can be detected in keratinocytes of equine sarcoid tumors. Vet Microbiol 2010; 146(3-4): 269-75.

[27] Bogaert L, Martens A, Van Poucke M, et al. High prevalence of bovine papillomaviral DNA in the normal skin of equine sarcoidaffected and healthy horses. Vet Microbiol 2008; 129(1-2): 58-68.

[28] O'Banion MK, Reichmann ME, Sundberg JP. Cloning and characterization of a papillomavirus associated with papillomas and carcinomas in the European harvest mouse (Micromys minutus). J Virol 1988; 62(1): 226-33.

[29] Iwasaki T, Maeda H, Kameyama Y, Moriyama M, Kanai S, Kurata T. Presence of a novel hamster oral papillomavirus in dysplastic lesions of hamster lingual mucosa induced by application of dimethylbenzanthracene and excisional wounding: molecular cloning and complete nucleotide sequence. J Gen Virol 1997; 78 ( Pt 5): 1087-93.

[30] Schulz E, Gottschling M, Wibbelt G, Stockfleth E, Nindl I. Isolation and genomic characterization of the first Norway rat (Rattus norvegicus) papillomavirus and its phylogenetic position within Pipapillomavirus, primarily infecting rodents. J Gen Virol 2009; 90(Pt 11): 2609-14.

[31] Ingle A, Ghim S, Joh J, Chepkoech I, Bennett Jenson A, Sundberg JP. Novel laboratory mouse papillomavirus (MusPV) infection. Vet Pathol. [Research Support, Non-U.S. Gov't] 2011; 48(2): 500-5.

[32] Joh J, Jenson AB, Proctor M, et al. Molecular diagnosis of a laboratory mouse papillomavirus (MusPV). Experimental and molecular pathology 2012; in press.

[33] Nafz J, Kohler A, Ohnesorge M, Nindl I, Stockfleth E, Rosl F. Persistence of Mastomys natalensis papillomavirus in multiple organs identifies novel targets for infection. J Gen Virol 2007; 88(Pt 10): 2670-8.

[34] Siegsmund M, Wayss K, Amtmann E. Activation of latent papillomavirus genomes by chronic mechanical irritation. J Gen Virol 1991; 72 ( Pt 11): 2787-9.

[35] Amtmann E, Volm M, Wayss K. Tumour induction in the rodent Mastomys natalensis by activation of endogenous papilloma virus genomes. Nature 1984; 308(5956): 291-2.

[36] Nicholls PK, Klaunberg BA, Moore RA, et al. Naturally occurring, nonregressing canine oral papillomavirus infection: host immunity, virus characterization, and experimental infection. Virology 1999 . 265(2): 365-74.

[37] Nicholls PK, Moore PF, Anderson DM, et al. Regression of canine oral papillomas is associated with infiltration of CD4+ and CD8+ lymphocytes. Virology 2001; 283(1): 31-9.

[38] Jahan-Parwar B, Chhetri DK, Hart S, Bhuta S, Berke GS. Development of a canine model for recurrent respiratory papillomatosis. Ann Otol Rhinol Laryngol 2003; 112(12): 1011-3.

[39] Johnston KB, Monteiro JM, Schultz LD, et al. Protection of beagle dogs from mucosal challenge with canine oral papillomavirus by immunization with recombinant adenoviruses expressing codonoptimized early genes. Virology 2005; 336(2): 208-18.

[40] Moore RA, Nicholls PK, Santos EB, Gough GW, Stanley MA. Absence of canine oral papillomavirus DNA following prophylactic L1 particle-mediated immunotherapeutic delivery vaccination. J Gen Virol 2002; 83(Pt 9): 2299-301.

[41] Moore RA, Walcott S, White KL, et al. Therapeutic immunisation with COPV early genes by epithelial DNA delivery. Virology 2003; 314(2): 630-5.

[42] Stanley MA, Moore RA, Nicholls PK, et al. Intra-epithelial vaccination with COPV L1 DNA by particle-mediated DNA delivery protects against mucosal challenge with infectious COPV in beagle dogs. Vaccine 2001; 19(20-22): 2783-92.

[43] Jain S, Moore RA, Anderson DM, Gough GW, Stanley MA. Cellmediated immune responses to COPV early proteins. Virology 2006; 356(1-2): 23-34

[44] Delius H, Van Ranst MA, Jenson AB, zur Hausen H, Sundberg JP. Canine oral papillomavirus genomic sequence: a unique $1.5-\mathrm{kb}$ intervening sequence between the E2 and L2 open reading frames. Virology 1994; 204(1): 447-52.

[45] Nicholls PK, Doorbar J, Moore RA, Peh W, Anderson DM, Stanley MA. Detection of viral DNA and E4 protein in basal keratinocytes of experimental canine oral papillomavirus lesions. Virology 2001; 284(1): 82-98.

[46] Peh WL, Middleton K, Christensen N, et al. Life cycle heterogeneity in animal models of human papillomavirusassociated disease. J Virol 2002; 76(20): 10401-16.

[47] Parsons RJ, Kidd JG. Oral papillomatosis of rabbits: a virus disease. Journal of Experimental Medicine 1942; 77: 233-50.

[48] Christensen ND, Cladel NM, Reed CA, Han R. Rabbit oral papillomavirus complete genome sequence and immunity following genital infection. Virology 2000; 269(2): 451-61.

[49] Maglennon GA, McIntosh P, Doorbar J. Persistence of viral DNA in the epithelial basal layer suggests a model for papillomavirus 
latency following immune regression. Virology 2011; 414(2): 15363.

[50] Shope RE, Hurst EW. Infectious Papillomatosis of Rabbits : With a Note on the Histopathology. J Exp Med 1933; 58(5): 607-24.

[51] Reuter JD, Gomez D, Brandsma JL, Rose JK, Roberts A. Optimization of cottontail rabbit papilloma virus challenge technique. J Virol Methods 2001; 98(2): 127-34.

[52] Syverton JT. The pathogenesis of the rabbit papilloma-tocarcinoma sequence. Ann N Y Acad Sci 1952; 54(6): 1126-40.

[53] Roberts JN, Kines RC, Katki HA, Lowy DR, Schiller JT. Effect of Pap smear collection and carrageenan on cervicovaginal human papillomavirus-16 infection in a rhesus macaque model. J Natl Cancer Inst 2011; 103(9): 737-43.

[54] Amella CA, Lofgren LA, Ronn AM, Nouri M, Shikowitz MJ, Steinberg BM. Latent infection induced with cottontail rabbit papillomavirus. A model for human papillomavirus latency. Am J Pathol 1994; 144(6): 1167-71.

[55] Zhang $P$, Nouri M, Brandsma JL, Iftner T, Steinberg BM. Induction of E6/E7 expression in cottontail rabbit papillomavirus latency following UV activation. Virology 1999; 263(2): 388-94.

[56] Selvakumar R, Schmitt A, Iftner T, Ahmed R, Wettstein FO. Regression of papillomas induced by cottontail rabbit papillomavirus is associated with infiltration of CD8+ cells and persistence of viral DNA after regression. J Virol 1997; 71(7): $5540-8$.

[57] Schmitt A, Rochat A, Zeltner R, et al. The primary target cells of the high-risk cottontail rabbit papillomavirus colocalize with hair follicle stem cells. J Virol 1996; 70(3): 1912-22.

[58] Koster MI. Making an epidermis. Ann N Y Acad Sci 2009; 1170 : 7-10.

[59] Watt FM, Lo Celso C, Silva-Vargas V. Epidermal stem cells: an update. Curr Opin Genet Dev 2006; 16(5): 518-24.

[60] Strickler HD, Burk RD, Fazzari M, et al. Natural history and possible reactivation of human papillomavirus in human immunodeficiency virus-positive women. J Natl Cancer Inst 2005; 97(8): 577-86.

[61] Leigh IM, Glover MT. Skin cancer and warts in immunosuppressed renal transplant recipients. Recent Results Cancer Res 1995; 139: 69-86.

[62] Dubina M, Goldenberg G. Viral-associated nonmelanoma skin cancers: a review. Am J Dermatopathol 2009; 31(6): 561-73.
[63] Harwood CA, Proby CM. Human papillomavirus and immunosuppression. In: Sterling J, Tyring SK, editors. Human papillomaviruses. London: Arnold 2001. pp. 102-17.

[64] Gissmann L, Diehl V, Schultz-Coulon HJ, zur Hausen H. Molecular cloning and characterization of human papilloma virus DNA derived from a laryngeal papilloma. J Virol 1982; 44(1): 393400.

[65] Mounts P, Shah KV, Kashima H. Viral etiology of juvenile- and adult-onset squamous papilloma of the larynx. Proc Natl Acad Sci USA 1982; 79(17): 5425-9.

[66] Cladel NM, Hu J, Balogh K, Mejia A, Christensen ND. Wounding prior to challenge substantially improves infectivity of cottontail rabbit papillomavirus and allows for standardization of infection. J Virol Methods 2008; 148(1-2): 34-9.

[67] Wilson VG, West M, Woytek K, Rangasamy D. Papillomavirus E1 proteins: form, function, and features. Virus Genes 2002; 24(3) 275-90.

[68] Egawa N, Nakahara T, Ohno S, et al. The E1 protein of human papillomavirus type 16 is dispensable for maintenance replication of the viral genome. J Virol 2012; 86(6): 3276-83.

[69] Wilgenburg BJ, Budgeon LR, Lang CM, Griffith JW, Christensen ND. Characterization of immune responses during regression of rabbit oral papillomavirus infections. Comp Med 2005; 55(5): 4319.

[70] Selvakumar R, Ahmed R, Wettstein FO. Tumor regression is associated with a specific immune response to the E2 protein of cottontail rabbit papillomavirus. Virology 1995; 208(1): 298-302.

[71] Amon W, Farrell PJ. Reactivation of Epstein-Barr virus from latency. Rev Med Virol 2005; 15(3): 149-56.

[72] Foster CA, Yokozeki H, Rappersberger K, et al. Human epidermal $\mathrm{T}$ cells predominantly belong to the lineage expressing alpha/beta $\mathrm{T}$ cell receptor. J Exp Med 1990; 171(4): 997-1013.

[73] Vinokurova S, von Knebel Doeberitz M. Differential methylation of the HPV 16 upstream regulatory region during epithelial differentiation and neoplastic transformation. PLoS One 2011; 6(9): e24451.

[74] Joh J, Jenson AB, King W, et al. Genomic analysis of the first laboratory-mouse papillomavirus. J Gen Virol 2011; 92(Pt 3): 6928.

(C) Maglennon and Doorbar; Licensee Bentham Open.

This is an open access article licensed under the terms of the Creative Commons Attribution Non-Commercial License (http://creativecommons.org/licenses/by$\mathrm{nc} / 3.0 /$ ) which permits unrestricted, non-commercial use, distribution and reproduction in any medium, provided the work is properly cited. 